\title{
Self-esteem of the ambition of Russian and Turkmen students
}

\author{
Oksana Barsukova ${ }^{1,}$, Elena Scherbina $^{1}$, Natalia Mozgovaya $^{1}$, Galina Zhulina ${ }^{1}$, Olesya \\ Shestopalopa ${ }^{2}$ \\ ${ }^{1}$ Southern Federal University, Rostov-on-Don, Russia \\ ${ }^{2}$ Don State Technical University, Rostov-on-Don, Russia
}

\begin{abstract}
The article presents the results of a cross-cultural study of selfassessment of ambition of Russian and Turkmen students. The purpose of the study is to identify the features of self-esteem of ambition and the degree of its expression among students from different countries. The research was carried out using the questionnaire "Ambition" (OV Barsukova). The study involved 166 students aged 17-19 years: 94 Russian students and 72 Turkmen students. The majority of Russian students consider themselves to be more ambitious than ambitious people (48.94\%), about a quarter of Russian students consider themselves to be unambitious people $(25.53 \%)$, and a fifth - more un ambitious than ambitious people (21.28\%)), the minimum number - by undemanding people (4.26\%). Most of the Russian students rate their ambition as moderate $(51.056 \%)$, the minimum part of the students - as low (12.77\%). On the whole, Russian students consider themselves ambitious rather than undemanding people and rate their ambition as moderate. The overwhelming majority of Turkmen students consider themselves to be ambitious people (83.33\%), an insignificant part of students consider themselves to be more ambitious people than unambitious $(11.11 \%)$ and undemanding people $(5.56 \%)$. The majority of Turkmen students rate their ambition as high $(61.11 \%)$, just over a quarter of them - as low (27.78\%), the minimum number - as moderate $(11.11 \%)$. In general, Turkmen students consider themselves ambitious and rate their ambition as high. A comparative analysis of the self-esteem of the ambition of Russian and Turkmen students was revealed according to the following indicators: the assessment of oneself as ambitious people prevails among Turkmen students, the assessment of oneself as people who are more ambitious than undemanding people prevails among Russian students, and the assessment of their ambition as moderate prevails among Russian students.
\end{abstract}

\section{Introduction}

Cross-cultural studies are the mainstream of research in psychology, sociology, anthropology and other sciences. For example, research by D. Matsumoto [1], N. Arunasalam [2], M. Simpson [3], M.J. Clark [4]. Separately, we can distinguish such a direction of cross-

\footnotetext{
* Corresponding author: knesinka@mail.ru
} 
cultural research as research in education. Examples of modern research include studies by D. Berque and colleagues [5], studies by Vincenzo G. Terán [6], studies by A. K. Belousova and Y. Tushnova with colleagues [7, 8], and others.

The relevance of these studies is determined by the fact that in modern conditions, citizens of various countries and States live and operate in the borders of several cultures, including the main one - the title one, and various ethnic ones. Ethnic groups, without being confined to the linguistic and cultural traditions of their ethnic group, gain experience in mastering the history, culture and languages of other peoples, based on the principles of multicultural and multilingual education.

One of the qualities that is in the focus of modern research in Russian psychology is ambition [9, 10]. Ambition is one of the motives of the social activity of an individual [10]. This is the desire of a person to be recognized as a person for other people for real actions and achievements that are important not only for this person himself, but also for others [10, $11]$.

So, the study of ambition is conditioned, on the one hand, by the need to study the psychological content of this phenomenon, the functions that it performs, its role as a motive for the social activity of a person $[9,10,11]$. Ashley Bell Jones etc. raises the question about the place of ambition in the structure of personality and suggest that ambition (ambitions) is not included in traditional models of personality [12]. M. Č. Dražić and colleagues consider the relationship of career ambitions with other personal characteristics of a person [13]. Junyi Chai considers human love (or ambition) in the context of a person's past experience, the influence on the different current situation [14]. K. Carroll analyzes ambition in the context of various aspects of socialization [15].

On the other hand, it is interesting how people assess their ambition. The few studies of the ambition of schoolchildren and university students, carried out within the framework of dissertation research, emphasize its positive role in personality development, and as recommendations note the need for purposeful education of this quality in the younger generation. In this regard, it seems interesting and necessary to analyze the self-assessment of students' ambition [11]. Ashley Bell Jones notes that ambition plays an important role in the educational and career success and status of the individual, connects ambition with social courage of the individual [12]. J. Blais and S. Pruysers in their research, for example, try to identify which personal characteristics affect the development of political ambitions of undergraduated students [16].

\section{Purpose of the study}

The aim of the research is to study the features of self-esteem of ambition and its expression among students from different states - Russia and Turkmenistan. We proceed from the assumption that there are differences in the assessment of oneself as an ambitious person of Russian and Turkmen students.

This study is the part of a broader study of the motivation of social activity of students from different countries. Along with ambition, we investigate the motivation for selfassertion of students, the desire for power, for money, etc.

\section{Methodology}

A study of self-reported of students' ambition was conducted in 2020. The "Ambition" questionnaire (OV Barsukova) was used as a methodology. Mathematical and statistical processing of the obtained results was carried out using Fisher's $\varphi$-test. 
The study involved 166 first-year students of the Southern Federal University (Rostovon-Don, Russia): 94 Russian students and 72 Turkmen students aged 17-19 years. Russian students are young people, citizens of the Russian Federation, permanently residing in the territory of the state, by religion are Orthodox. Turkmen students are young people, citizens of Turkmenistan who came to study in the Russian Federation, by religion are Muslims.

\section{Results}

The study of self-esteem of Russian students showed the following results:

About half of Russian students consider themselves ambitious rather than unambitious (48.94\%). A quarter of students consider themselves less ambitious than ambitious people $(25.53 \%)$. The fifth part of students consider themselves ambitious $(21.28 \%)$. The minimum number of students is unambitious $(4.26 \%)$.

In assessing of the severity of their ambition, Russian students prefer to assess their ambition as moderate $(51.06 \%)$. Just over the third part of Russian students rate their ambition as high $(36.17 \%)$. Finally, the minimum number of Russian students rate their ambition as low (12.77\%).

So, the majority of Russian students consider themselves to be more ambitious than unambitious people, and evaluate their ambition as moderate (average).

The study of self-assessment of Turkmen students showed the following results:

The vast majority of Turkmen students consider themselves ambitious people (83.33\%). The minimum number of Turkmen students consider themselves ambitious rather than unambitious people (11.11\%) and unambitious people (5.56\%).

More than half of Turkmen students rate their ambition as high $(61.11 \%)$. Just over the fifth part of Turkmen students rate their ambition as low $(27.78 \%)$, while the minimum number of Turkmen students rate their ambition as moderate $(11.11 \%)$.

So, the majority of Turkmen students consider themselves ambitious people and rate their ambition as high.

A comparative analysis of the self-assessment of ambition of Russian and Turkmen students showed the following results (Fig.1):

Self-assessment as an ambitious person prevails among Turkmen students $(83.33 \%)$ compared to Russian students $(21.28 \%)$. These differences are statistically significant $(\varphi=4.838, \mathrm{p}=0.01)$.

Russian students ' assessment of themselves as ambitious rather than unambitious (48.94\%) compared to Turkmen students (11.11\%). These differences are statistically significant $(\varphi=3.139, \mathrm{p}=0.01)$.

The assessment of oneself as a unambitious person is expressed, in fact, in equal proportion of Russian students $(4.26 \%)$ and Turkmen students $(5.56 \%)$. These differences are not statistically significant $(\varphi=0.124, \mathrm{p}=0.05)$.

Only Russian students $(25.53 \%)$ rated themselves as unambitious rather than ambitious. 


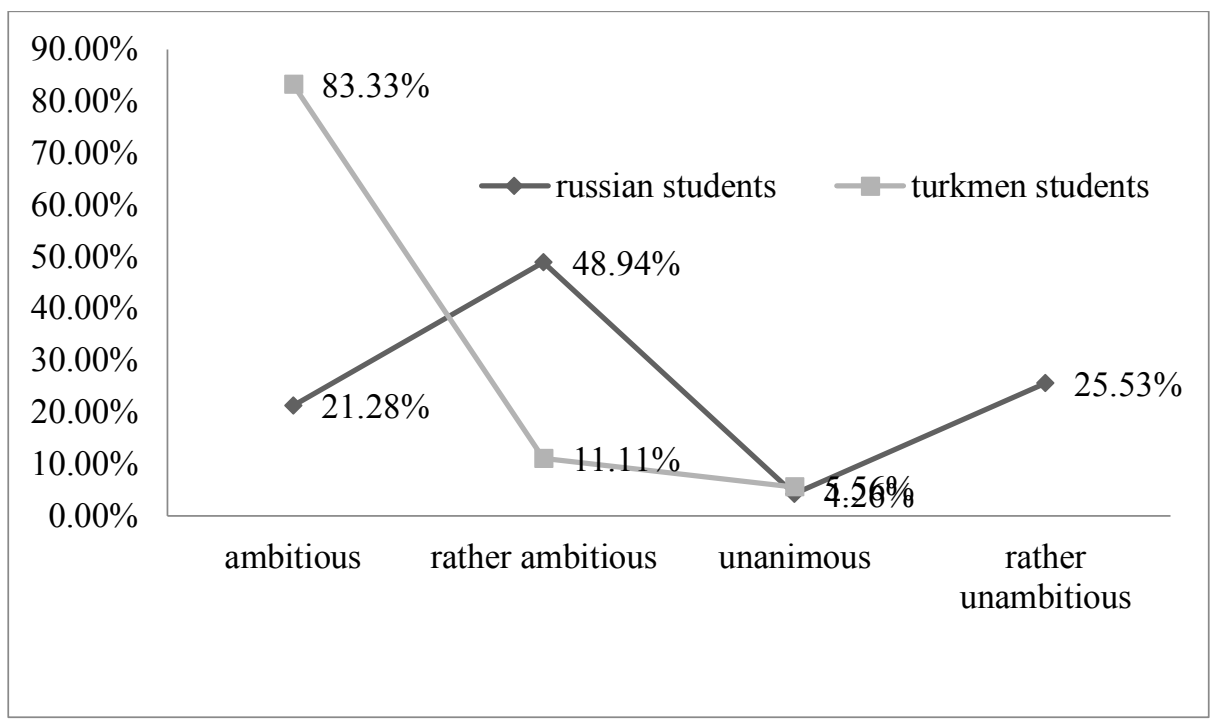

Fig. 1. Self-assessment of the ambition of Russian and Turkmen students.

A comparative analysis of the self-assessment of the expression of their ambition of Russian and Turkmen students showed the following results (Fig.2):

The assessment of their ambition as high prevails among Turkmen students $(66.11 \%)$ compared to Russian students $(36.17 \%)$. These differences are not statistically significant $(\varphi=1.423, \mathrm{p}=0.05)$.

The assessment of their ambition as moderate prevails among Russian students $(51.06 \%)$ compared to Turkmen students $(11.11 \%)$. These differences are statistically significant $(\varphi=3.297, \mathrm{p}=0.01)$.

The assessment of their ambition as low prevails among Turkmen students $(27.78 \%)$ compared to Russian students $(12.77 \%)$. These differences are not statistically significant $(\varphi=1.367, \mathrm{p}=0.05)$.

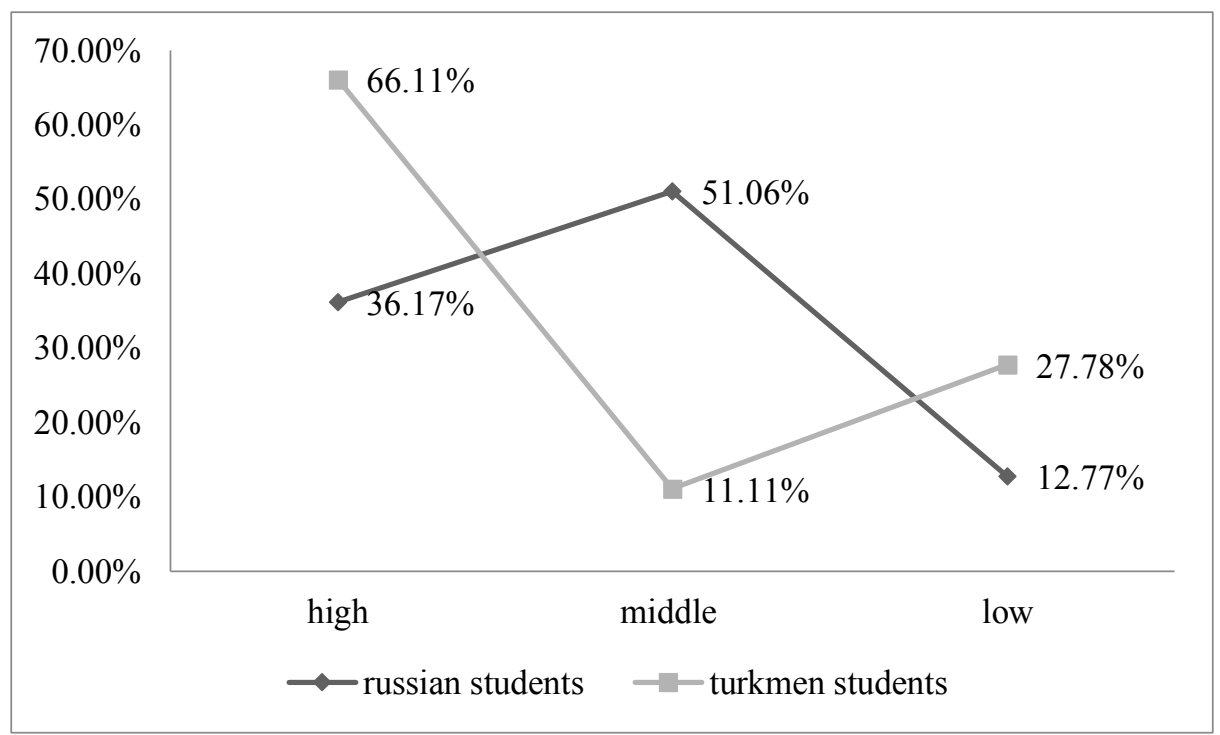

Fig. 2. The self-assessment of the level of ambition of Russian and Turkmen students. 
Thus, statistically significant differences in the self-assessment of ambition of Russian and Turkmen students were revealed by the following indicators:

Self-esteem as an ambitious person prevails among Turkmen students. The assessment of oneself as an ambitious rather than unambitious person prevails among Russian students. The assessment of oneself as a unambitious rather than ambitious person is presented only among Russian students. The assessment of their ambition as moderate prevails among Russian students.

\section{Discussion}

Our results partially confirmed our assumption about differences in the self-assessment of students ' ambition in different countries - Turkmen students consider themselves more ambitious people than Russian students.

These differences and the high estimation of ambition by Turkmen students can be explained by the change in the social status of Turkmen students. They did not just become University students, they came to study and receive higher education in another state, which obviously required them to show some qualities that will help them be active in a new social reality for them.

\section{Conclusion}

Most Russian students consider themselves ambitious rather than unambitious, and rate their ambition as moderate. Most Turkmen students consider themselves ambitious people and rate their ambition as high.

The main differences in self-esteem as an ambitious person are as follows: Most Turkmen students consider themselves ambitious compared to Russian students. Most Russian students, compared to Turkmen students, consider themselves ambitious rather than dishonest. Only Russian students consider themselves unambitious rather than ambitious people. Turkmen students do not have such a description of themselves. The assessment of their ambition as moderate prevails among Russian students.

\section{References}

1. D. Matsumoto, Culture and Psychology (Wadsworth Publishing, 2007) ISBN: 9780495097877, EAN: 9780495097877

2. N. Arunasalam, Nurse Researcher 27(2) (2019) DOI: 10.7748 / nr.2019.e1605

3. M. Simpson, T Ake Whitiwhiti, Journal of Intercultural Communication Research 39(3), 185-205 (2010) DOI: 10.1080/17475759.2010.534861

4. M.J. Clark, International Journal of Nursing Practice 18(2), 28-37 (2012) DOI: 10.1111/j.1440-172X.2012.02026.x

5. D. Berque, H. Chiba, M. Ohkura, P. Sripian, M. Sugaya, Robot Design Lecture Notes in Computer Science (including subseries Lecture Notes in Artificial Intelligence and Lecture Notes in Bioinformatics) 12192, 553-563 (2020) DOI: 10.1007/978-3-03049788-0_42

6. V.G. Terán, E.E. Velásquez, M.A. Fuentes, Personality and Individual Differences 110102 (2020) https://doi.org/10.1016/j.paid.2020.110102 
7. A.K. Belousova, E.P. Kryschenko, O.V. Barsukova, Y.A. Tushnova et al., INTED2017 Proceedings. 11th International Technology, Education and Development Conference (Valencia, Spain, 2017) DOI: 10.21125/inted.2017.0298

8. A.K. Belousova, E.P. Kryschenko, O.V. Barsukova, Y.A. Tushnova et al., INTED2017 Proceedings. 11th International Technology, Education and Development Conference (Valencia, Spain, 2017) DOI: 10.21125/inted.2017.0083

9. E. Ilyin, The psychology of envy, hostility, vanity (Piter, SPb, 2014) ISBN 978-5-49600712-2

10. O. Barsukova, N. Mozgovaya, L. Kosikova, Culture and Education : Social Transformations and Multicultural Communication : Proceedings of the Middle-Term Conference RC04 Sociology of Education International Sociological Association (ISA) (Institute of Foreign Languages RUDN University, Moscow, 2019) DOI: 10.22363/09669-2019-306-312

11. O. Barsukova, Journal of Process Management - New Technologies, International 5(3), 1-3 (2017) http://www.japmnt.com/index.php/component/content/article/86-issues/232volume-5-issue-3-2017

12. A. Bell Jones, R.A. Sherman, R.T. Hogan, Personality and Individual Differences 106(1), 26-31 (2017) doi.org/10.1016/j.paid.2016.09.057

13. M.Ć. Dražić, I.B. Petrović, M. Vukelić, Frontiers in Psychology 9, 1729 (2018) DOI: 10.3389 / fpsyg.2018.01729

14. J. Chai, European Journal of Operation Research 288(2), 692-702 (2021) doi.org/10.1016/j.ejor.2020.06.009

15. K. Carroll, American Review of Public Administration 47(2), 209-229 (2017) DOI: $10.1177 / 0275074016671602$

16. J. Blais, S. Pruysers, Personality and Individual Differences 113, 167-172 (2017) doi.org/10.1016/j.paid.2017.03.029 